\title{
Effects of 0.5\% Heavy Bupivacaine At Room Versus Body Temperature on Shivering After Spinal Anesthesia In Patients Undergoing Caesarean Section
}

Dr. Basman Saed ,Dr. Khoula Al-Manthari, Anaesthesia and ICU department, Khoula Hospital, Muscat, Sultanate Of Oman

\section{INTRODUCTION}

Shivering is a frequent problem associated with central neuraxial block that is uncomfortable for patients, with an incidence reaching up to $56.7 \%$ perioperatively.

\section{OBJECTIVES}

In this prospective, randomized, double blinded study, we evaluate the effect of warm (body temperature $37^{\circ} \mathrm{C}$ ) Vs cold (room temperature $23^{\circ} \mathrm{C}$ ) $0.5 \%$ heavy bupivacaine injected intrathecally, on Post Anesthesia Shivering (PAS) in patients undergoing Caesarean Section. Secondary outcomes such as pruritus, nausea and vomiting are also evaluated.

\section{METHODS}

We enrolled 100 patients with ASA I \& II between age range of 20 -35 yrs undergoing elective/emergency LSCS , Patients were randomly divided into two groups:

Body Temperature Group (BT):

$(n=50)$ : received $2 \mathrm{ml}$ of $0.5 \%$ heavy bupivacaine $+20 \mathrm{mcg}$ fentanyl intrathecal at $37^{\circ} \mathrm{C}$. Room Temperature Group (RT):

$(\mathrm{n}=50)$ : received $2 \mathrm{ml}$ of $0.5 \%$ heavy bupivacaine $+20 \mathrm{mcg}$ fentanyl intrathecal at $23^{\circ} \mathrm{C}$.

$\checkmark$ For both groups, operating room kept constantly warm, IV fluid pre warmed

$\checkmark$ Subarachnoid block was performed using warmed L.A by tissel kit warming machine for BT group , conventional method used for RT group. Patient core temperature was monitored by the tympanic membrane probe

$\checkmark$ Parameters recorded : Sensory block level, blood pressure, heart rate, Apgar score blood loss, nausea, vomiting, pruritus, core temperature, shivering with intensity (Grade 0-4).

$\checkmark$ Shivering was evaluated according to the shivering scale developed by Crossley and Mahajan :-

0 No shivering

1 No visible muscle activity but piloerection, peripheral vasoconstriction, or both are present

2 Muscular activity in only one muscle group

3 Moderate muscular activity in more than one muscle group but no generalized shaking

4 Violent muscular activity that involves the whole body

\section{REFERENCES}

1. NSY Padayachee et al. Postoperative Anaesthesia Shivering, University of Kwazulu Natal 03 May 2013, No 15

2. CrowleyLJ, Buggy DL, Shivering and neuraxial anaesthesia. Regional Anesthesia and Pain Medicine 2008; 33 (3): 241-52.

3. Mirzaie et al. The effects of warm and cold intrathecal bupivacaine on shivering during delivery under spinal anaesthesia. Saudi Journal of Anaesthesia 2012; 6 (4) : 336-340

\section{RESULTS}

There was no difference between two groups in amount of blood loss, vitals and Apgar score , but the incidence of pruritus was more, and dermatomal level achieved was slightly higher in the RT group..

The incidence \& intensity of shivering is obviously and significantly reduced in BT group

\begin{tabular}{|l|l|c|c|}
\hline Parameters & Group BT & Group RT & P value \\
\hline Mean Age (year) & $33.58 \pm 5$ & $31.62 \pm 6$ & 0.231 \\
\hline Mean weight (Kg) & $79 \pm 23$ & $82 \pm 21$ & 0.604 \\
\hline Mean temperature at 0 min & $35.2 \pm 1.2$ & $36.2 \pm 0.8$ & 0.002 \\
\hline Median shivering at 0 $\mathrm{min}$ & 0 & 0 & 0.808
\end{tabular}

\begin{tabular}{|c|c|c|c|c|c|}
\hline \multirow[t]{2}{*}{ Parameters } & \multicolumn{2}{|c|}{ BT Group $(n=50)$} & \multicolumn{2}{|c|}{ RT Group (n=50) } & \multirow[t]{2}{*}{$P$ value } \\
\hline & No. & $\%$ & No. & $\%$ & \\
\hline $\begin{array}{l}\text { Patients with shivering } \\
\text { (Grades I to IV included) }\end{array}$ & 7 & 14 & 31 & 62 & $\underline{0.0001}$ \\
\hline Patients with pruritus & 3 & 6 & 10 & 20 & $\underline{0.037}$ \\
\hline Patients with nausea & 13 & 26 & 14 & 28 & 0.822 \\
\hline Patients with vomiting & 3 & 6 & 6 & 12 & 0.295 \\
\hline Dermatomal level achieved & \multicolumn{2}{|c|}{ T5-T6 } & \multicolumn{2}{|c|}{ T4-T5 } & \\
\hline
\end{tabular}

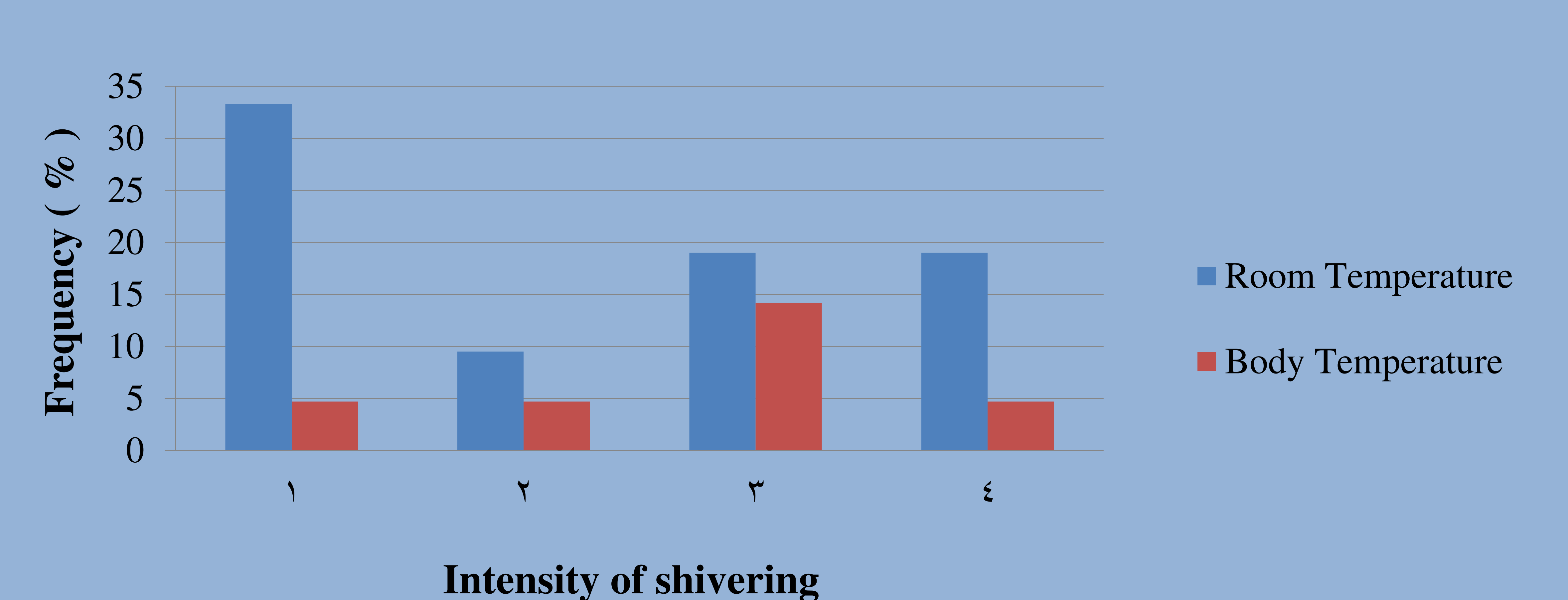

CONCLUSION

Warming hyperbaric $0.5 \%$ bupivacaine to body temperature can reduce the incidence and intensity of shivering in women undergoing caesarean delivery under spinal anesthesia as compared to that administered at room temperature. 